\title{
Enhanced Ionic Transport Mechanism by Gramicidin A Confined Inside Nanopores Tuned by Atomic Layer Deposition
}

\author{
Adib Abou Chaaya, ${ }^{\#, \dagger}$ Mathilde Le Poitevin, $\#, \dagger$ Simon Cabello-Aguilar, ${ }^{\dagger}$ Sebastien Balme, ${ }^{*}, \dagger, \ddagger$ \\ Mikhael Bechelany, ${ }^{* \dagger}$ Sebastian Kraszewski, ${ }^{\S}$ Fabien Picaud, ${ }^{\S}$ Julien Cambedouzou," \\ Emmanuel Balanzat, ${ }^{\perp}$ Jean-Marc Janot, ${ }^{\dagger}$ Thierry Thami, ${ }^{\dagger}$ Philippe Miele, ${ }^{\dagger}$ and Philippe Dejardin ${ }^{\dagger}$ \\ ${ }^{\dagger}$ Institut Européen des Membranes, UMR5635 CNRS-UM2-ENSCM, Place Eugène Bataillon, 34095 Montpellier cedex 5, France \\ ${ }^{\ddagger}$ Institut Charles Gerhardt, UMR 5253 CNRS-UM2-ENSCM-UM1, Place Eugène Bataillon, 34095 Montpellier cedex 5, France \\ ${ }^{\S}$ Laboratoire de Nanomédecine, Imagerie et Thérapeutique, Université Franche-Comté, Centre Hospitalier Universitaire de \\ Besançon, 16 route de Gray, 25030 Besançon cedex, France \\ "Institut de Chimie Séparative de Marcoule, Laboratoire de Diffusion-Diffraction, UMR 5257 CEA-CNRS-UM2-ENSCM Bagnols sur \\ Cèze, France \\ ${ }^{\perp}$ Centre de recherche sur les Ions, les MAtériaux et la Photonique, UMR6252 CEA-CNRS-ENSICAEN, 6 Boulevard du Maréchal \\ Juin, 14050 Caen Cedex 4, France
}

\section{Supporting Information}

ABSTRACT: The confinement and the understanding of ion transport through ionic channels when they are confined inside solid-state nanopores smaller than $10 \mathrm{~nm}$ remains a challenge. Here we report on the fabrication of biomimetic nanopores with high length $(5 \mu \mathrm{m}) /$ diameter (smaller than $10 \mathrm{~nm}$ ) ratio obtained using both a track-etched technique and atomic layer deposition on flexible membranes. These membranes present uniform hydrophobic nanopores with a low roughness inside the pores. Gramicidin A is then confined inside nanopores (diameter 10.6, 5.7, and $\sim 2 \mathrm{~nm}$ ) leading to the $\mathrm{NaCl}$ ionic transport mechanism through a hybrid nanopore similar to the biological ones especially for small diameter (5.7 and $\sim 2 \mathrm{~nm}$ ).

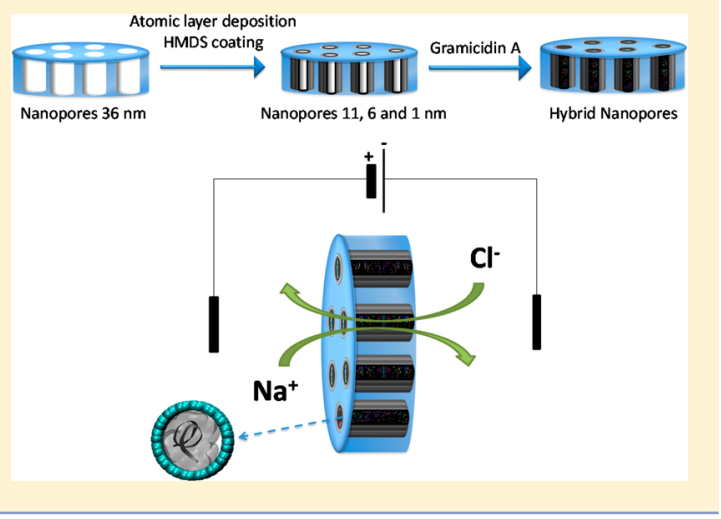

\section{INTRODUCTION}

Solid-state membrane technologies are commonly used in many industrial, health, or environmental applications. Thus, the development of membranes which present both high ion permeability and high selectivity without energy intake has been an important research topic for many years. ${ }^{1}$ Nevertheless, these features are often considered as antagonist. To mimic ionic channel properties, owing to unique selectivity and permeability, one strategy is to design a conical track-etched pore $^{2}$ with charge surface modification or polymer grafting. These membranes exhibit ionic diode properties where the anionic or cationic selectivity is obtained under an electric field. Another strategy based on direct confinement of biological ionic channels inside cylindrical nanopores has been recently proved. ${ }^{3,4}$ This way aims to combine robustness, suitability (material), and selectivity (biology) properties. ${ }^{5,6}$

Among ionic channels, gramicidin A (gA) is one of the most widely studied due to its simple structure and to its selectivity to a monovalent cation. ${ }^{7-9}$ To make it short, gA is formed by a linear polypeptide of 15 hydrophobic amino acids which adopt $\beta$-helix structure. Inside the lipid membrane, the selective pore is formed by a head-head dimer of gA linked by a H-bond between C-terminal functions. With this conformation, a gA channel is only permeable to monovalent cations ${ }^{10,11}$ and blocks anions. ${ }^{12}$ Even though gA is one of the simplest ionic channels, its properties are not easily transferred to solid-state membranes. Recently, we reported the first studies about the synthesis of hybrid membranes by confining gA in the pores of track-etched membranes. ${ }^{3,13}$ The latter membrane made of polycarbonate has several advantages related to its uniformity and density of nanopores, wide diameter pore range, flexibility, and low cost of fabrication. These first studies have opened many questions about ionic transport mechanisms and the influence of the larger nanopore diameter $(15 \mathrm{~nm})$ than $\mathrm{gA}$ (close to $1 \mathrm{~nm}$ ). In the present study, we propose to investigate the ionic transport mechanisms of confined gA inside the sub$10 \mathrm{~nm}$ hydrophobic nanopore.

Besides, surface modification of porous membranes for different applications like separation processes, ${ }^{14}$ nanotube template elaboration, ${ }^{15}$ and energy storage $^{16}$ has attracted

Received: April 4, 2013

Revised: June 18, 2013

Published: July 8, 2013 
Table 1. Nanopore Membranes Used in This Study

\begin{tabular}{|c|c|c|c|c|c|c|c|}
\hline nanopore & initial pore diameter & ALD layer & mean pore diameter after HMDS grafting $(\mathrm{nm})$ & pore length $(\mu \mathrm{m})$ & pore number & $\kappa_{\exp }(\mathrm{pm})$ & $\kappa_{\text {th }}(\mathrm{pm})$ \\
\hline $\mathrm{nP}_{11}$ & 36 & 12.4 & 10.6 & 5 & 104 & 11.95 & 19.8 \\
\hline $\mathrm{nP}_{6}$ & 36 & 14.9 & 5.7 & 5 & 114 & 8.781 & 6.2 \\
\hline $\mathrm{nP}_{2}$ & 36 & 17 & $\sim 2$ & 5 & 106 & 7.120 & 0.26 \\
\hline
\end{tabular}

considerable interest in the last 20 years. A variety of techniques have been employed to modify the pore size and surface properties of porous membranes such as chemical vapor deposition, ${ }^{17}$ sol gel procedure, ${ }^{18}$ and atomic layer deposition (ALD). ${ }^{15}$ Among them, ALD has attracted particular attention for the growth of ultrathin homogeneous films based on two separated self-limiting surface reactions. This self-limiting surface reaction in ALD provides conformal deposition on high aspect ratio structures with a high degree of thickness control in the subnanometer range. ${ }^{19}$ A large number of metal oxides are used in ALD for different applications such as sensors, ${ }^{20-22}$ solar cells, ${ }^{23-25}$ fuel cells, ${ }^{26,27}$ DRAM capacitors, ${ }^{28}$ and photocatalysis. ${ }^{29,30}$ In addition, ALD on polymers has been widely used for gas diffusion barriers, ${ }^{31}$ encapsulation organic light-emitting diodes, ${ }^{32,33}$ organic solar cells, ${ }^{34}$ dielectric gate in polymer-based transistors, ${ }^{35}$ enhancement of the photoprotection, and finally nanomechanical properties of polycarbonate. $^{36}$

In this paper, 100 nanopores have been obtained by track etching of poly(ethyleneterephthalate) (PET) film. We have investigated the deposition of a multilayer aluminum oxide/zinc oxide by $\mathrm{ALD}^{37,38}$ to reduce the pore diameter of the PET membrane from $36 \mathrm{~nm}$ down to diameters smaller than $10 \mathrm{~nm}$. The method used assures a low roughness inside the nanopores, preserving the main advantages of the polymeric membranes: uniformity of the nanopores and flexibility of the membrane. Then a hexamethyldisilazane chemical treatment ${ }^{39}$ allows us to coat the nanopore wall with $-\mathrm{CH}_{3}$ to mimic $-\mathrm{CH}_{2}-/ \mathrm{gA}$ interaction such as a lipid membrane. The membrane ionic transport and selectivity of $\mathrm{NaCl}$, before and after gA confinement, has been studied and is discussed based on the Michaelis-Menten model of ionic cotransport.

\section{MATERIALS AND METHODS}

Materials. Diethyl zinc (DEZ) $\left(\mathrm{Zn}\left(\mathrm{CH}_{2} \mathrm{CH}_{3}\right)_{2}, 95 \%\right.$ purity, CAS: 557-20-0) was purchased from Sterm chemical. Trimethylaluminum (TMA) $\left(\mathrm{Al}\left(\mathrm{CH}_{3}\right)_{3}, 97 \%\right.$ purity, CAS: 75-24-1), gramicidin A (50845), sodium chloride (S9888), methanol (179337), and hexamethyldisilazane (HMDS) (reagent grade, $\geq 99 \%$ ) were obtained from Sigma Aldrich. Demineralized water was obtained by Milli-Q system (Millipore). PET film (thickness $5 \mu \mathrm{m}$ ) was purchased from Goodfellow.

PET Nanopore Production. Using the track technique on poly(ethyleneterephthalate) (PET) film with krypton irradiation and chemical etching with $\mathrm{NaOH}$ solution, we obtained around 100 nanopores over an area of $1 \mathrm{~mm}^{2}$ (Table 1). For a typical preparation, a PET film (thickness $5 \mu \mathrm{m}$, length $24 \mathrm{~cm}$, width $4 \mathrm{~cm}$ ) is positioned on the trajectory of a diffracted ${ }^{78}$ Krypton ion $(9.5 \mathrm{MeV}$ ) beam in GANIL (Caen, France). A detector is set behind the film to count the number of ions crossing the film. When the number of counts (number of pores) is reached, here close to 100 , the beam is stopped. Afterward the film is moved to make another track $2 \mathrm{~cm}$ downward. The PET film is kept in an inert helium atmosphere to preserve the tracks. The chemical etching is obtained as follows: the tracked film is exposed on both sides for $24 \mathrm{~h}$ to an ultraviolet light (Fisher bioblock; VL215.MC, $312 \mathrm{~nm}$ ) then immersed during $5 \mathrm{~min}$ in $\mathrm{NaOH}$ solution $(3 \mathrm{M})$ at $50{ }^{\circ} \mathrm{C}$. At the end the film is rinsed with demineralized water.

Tuning the Nanopore Diameter Using ALD. A custommade ALD setup ${ }^{40}$ was used for synthesizing thin $\mathrm{Al}_{2} \mathrm{O}_{3} / \mathrm{ZnO}$ films. The $\mathrm{Al}_{2} \mathrm{O}_{3}$ ALD films were deposited using alternating exposures of TMA and deionized water $\left(\mathrm{H}_{2} \mathrm{O}\right)$ with the following cycle times: $0.1 \mathrm{~s}$ pulse (TMA), $20 \mathrm{~s}$ exposure, and 40 s purge with $100 \mathrm{sccm}$ dry Argon. A $2 \mathrm{~s}$ pulse, $30 \mathrm{~s}$ exposure, and $60 \mathrm{~s}$ purge with dry argon were used for $\mathrm{H}_{2} \mathrm{O}$. The $\mathrm{ZnO}$ ALD films were deposited using alternating exposures of DEZ and deionized water $\left(\mathrm{H}_{2} \mathrm{O}\right)$ with the following cycle times: $0.2 \mathrm{~s}$ pulse (DEZ), $20 \mathrm{~s}$ exposure, and $40 \mathrm{~s}$ purge. Again a $2 \mathrm{~s}$ pulse, $30 \mathrm{~s}$ exposure, and $60 \mathrm{~s}$ purge with dry argon were used for $\mathrm{H}_{2} \mathrm{O}$. ALD was carried out at $60{ }^{\circ} \mathrm{C}$. These pulses, exposure, and purge times were chosen conservatively to ensure completion of the ALD surface reactions and to prevent mixing of the reactive gases. The growth per cycle was about 2 $\AA /$ cycle for $\mathrm{Al}_{2} \mathrm{O}_{3}$ and $2.1 \AA /$ cycle for $\mathrm{ZnO}{ }^{37,41}$

A sequence of five cycles of $\mathrm{Al}_{2} \mathrm{O}_{3}$ preceding five cycles of $\mathrm{ZnO}$ was used to reduce the pore diameter. Three films of $\mathrm{Al}_{2} \mathrm{O}_{3} / \mathrm{ZnO}$ with different sequence numbers $(5,6$, and 7) were deposited on the PET membrane. After ALD deposition, a $24 \mathrm{~h}$ HMDS vapor exposure treatment was performed at room temperature to create a hydrophobic pore surface with a $-\mathrm{Si}\left(\mathrm{CH}_{3}\right)_{3}$ bond. The bilayer chemical composition was analyzed by EDX (Hitachi 4500 coupled with a Thermofisher EDX detector). The bilayer thickness was measured by SAXS (Xenocs GenX equipped with a molybdenum anode and a MAR2300 2D imaging plate detector). The HMDS nanopores modification was approved by XPS measurement (ESCALAB 250 Thermo Electron) and the determination of a contact angle. Contact angle measurement (GBX - Digidrop, Romans, France) was performed by applying a water droplet of $2.3 \mu \mathrm{L}$ to the surface. The contact angle was calculated using computerized image analysis. AFM measurements (AFM NANOMAN 5 from Veeco instrument controlled with a Nanoscope $\mathrm{V}$ software) were performed to obtain the roughness of the surface.

Gramicidin Confinement. gA confinement throughout the PET nanopore reduced by ALD and coated by HMDS has been performed as follows: The gA solution was prepared by mixing $10 \mathrm{~mL}$ of pure water $(\mathrm{pH} \sim 8)$ and $10 \mu \mathrm{L}$ of methanolic gA solution $\left(10^{-4} \mathrm{M}\right)$. The membrane was impregnated with the solution during $72 \mathrm{~h}$ at $6{ }^{\circ} \mathrm{C}$.

Membrane Conductivity Measurement. The recording of intensity/voltage $(I / V)$ curves has been performed on a potentiostat EG\&Gprinceton applied research model $236 \mathrm{~A}$. These measurements used two Ag/AgCl electrodes (Tacussel), which have been prepared to have an asymmetry potential less than $1 \mathrm{mV}$. The two compartments of the measurement cell have been separated by the PET film containing $\sim 100$ nanopores (Table 1). Nanopore conductance $(G)$ is directly given by the slope of the $I / V$ curve. Both compartments were filled with $12 \mathrm{~mL}$ of saline solution at the same concentration 


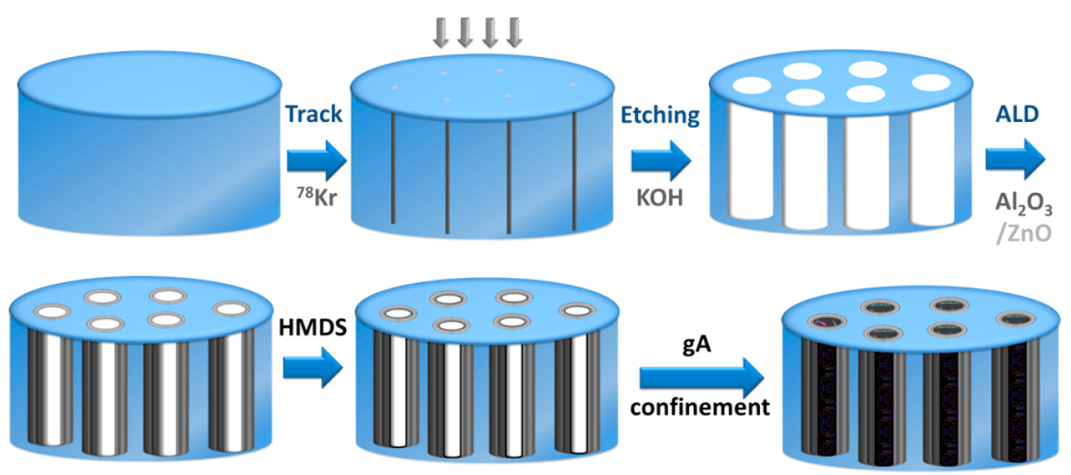

Figure 1. Schematic process for hybrid membrane synthesis.

from 0.9 to $300 \mathrm{mM}$ ( $\mathrm{pH} \sim 8)$. The current was recorded for a voltage ramp between -250 and $250 \mathrm{mV}$ with a step of 5 $\mathrm{mV} \cdot \mathrm{s}^{-1}$. The conductance $G$ in the manuscript corresponds to one pore for sake of comparison between the different membranes $\left(\mathrm{nS} \cdot\right.$ pore $\left.^{-1}\right)$. All experiments have been performed three times; the temperature was $24 \pm 1{ }^{\circ} \mathrm{C}$.

Ion Selectivity Measurement. The ion selectivity was obtained by the measurement of the voltage $\left(E_{0}\right)$ collected at $I$ $=0 \mathrm{~A}$. These acquisitions were performed with the same cell; the compartments were filled with asymmetric $\mathrm{NaCl}$ solutions (compartment "in" $250 \mathrm{mM}$ and compartment "out" $0.9 \mathrm{mM}$ ). Measurements were recorded with a EPC800 patch clamp amplifier (HEKA). The reversal potential $E_{\text {rev }}$ was calculated according to eq 1 .

$$
E_{0}=E_{\text {rev }}+\Delta E_{\mathrm{p}}
$$

where $E_{0}$ is the measured voltage and $\Delta E_{\mathrm{p}}$ is the junction potential induced by the difference of salt concentration between both compartments of the measurement cell, calculated according to eq 2 . In the present case the junction potential can be obtained by calculation because the zero of patch-clamp experiment is adjusted using a PET film without nanopore. $^{42}$

$$
\Delta E_{\mathrm{p}}=\frac{R T}{F} \frac{\left(\mu_{+}-\mu_{-}\right)}{\left(\mu_{+}+\mu_{-}\right)} \ln \frac{[\mathrm{NaCl}]_{\mathrm{i}}}{[\mathrm{NaCl}]_{\mathrm{o}}}
$$

where $\mu_{-}$and $\mu_{+}$are the relative mobility of the anion and cation, respectively. $R$ represents the gas constant; $T$ is the temperature; and $F$ is the Faraday constant.

The relative contribution of ions to the conductance is given by the ratio of their permeability coefficient $P_{\text {ion }}$. To obtain these relative permeations, data analyses have been performed using the Goldman-Hodgin-Katz (eq 3). ${ }^{43}$

$$
E_{\mathrm{rev}}=\frac{R T}{F} \ln \frac{\frac{P_{\mathrm{Na}}}{P_{\mathrm{Cl}}}\left[\mathrm{Na}^{+}\right]_{\mathrm{i}}+\left[\mathrm{Cl}^{-}\right]_{\mathrm{o}}}{\frac{P_{\mathrm{Na}}}{P_{\mathrm{Cl}}}\left[\mathrm{Na}^{+}\right]_{\mathrm{o}}+\left[\mathrm{Cl}^{-}\right]_{\mathrm{i}}}
$$

where $P_{\mathrm{X}}$ is the permeation of ion $\mathrm{X}$, and $[\mathrm{X}]_{\mathrm{i} / \mathrm{o}}$ represents $\mathrm{X}$ ion concentration inside the "in" and the "out" compartments, respectively $\left(\mathrm{X}=\mathrm{Na}^{+}\right.$or $\left.\mathrm{Cl}^{-}\right)$. Here, the measurement of relative permeation between sodium and chloride is determined from $E_{\text {rev }}$ when the membrane is placed between two compartments filled with a given electrolyte of ion concentration in the "in" compartment $[\text { ion }]_{\mathrm{i}}(250 \mathrm{mM})$ and of the salt concentration in the "out" compartment $[\text { salt }]_{\mathrm{o}}(0.9 \mathrm{mM})$.

Molecular Dynamics Simulations. The full atomistic molecular dynamics (MD) simulations were performed using
NAMD $2.7 \mathrm{~b} 2$ software. ${ }^{44}$ To encapsulate the proteins in the pore of different diameters, constant temperature of $300 \mathrm{~K}$ (Langevin dynamics) and constant pressure of $1 \mathrm{~atm}$ (using the Langevin piston Nosé-Hoover method ${ }^{45}$ ) were used to recover experimental conditions. We calculated the short- and the long-range forces every 1 and 2 time steps, respectively, with a time step of 2.0 fs. To evaluate the long-range electrostatic forces, the classical particle mesh Ewald (PME) method $^{46}$ was used, while chemical bonds between hydrogen and heavy atoms were constrained to their equilibrium value.

All systems (ions, water, membrane, gA) were modeled using the CHARMM $27^{47}$ force field. For water molecules, we applied the commonly used TIP3P model. No charge was attributed to the nanopore carbon atoms. For nanopore carbons $(\mathrm{C}-\mathrm{C})$ or nanopore carbon vs water oxygen $(\mathrm{C}-\mathrm{O})$ interactions, we used the Bedrov et al. ${ }^{48,49}$ Lennard-Jones potential parameters (CHARMM27 functional: $\sigma_{\mathrm{CC}}=3.895 \AA$, $\varepsilon_{\mathrm{CC}}=0.066 \mathrm{kcal}$ $\mathrm{mol}^{-1}$ and $\left.\sigma_{\mathrm{CO}}=3.58 \AA, \varepsilon_{\mathrm{CO}}=0.0936 \mathrm{kcal} \mathrm{mol}^{-1}\right)$. For the proteins, only the monomeric gA conformation (PDB code: 1JNO) was used, corresponding to the equilibrium geometry adopted in the water solvent. ${ }^{50}$ The gA monomers were first pre-equilibrated for at least $5 \mathrm{~ns}$ and then were extracted and inserted into the suitable simulation box containing the nanopore and the solvent, as described below.

To accelerate the calculations and prove the influence of the pore diameter on the protein structural arrangement, we choose arbitrarily to mimic the experimental nanopore by neither (i) a $(16,16)$ (pore diameter $2.1 \mathrm{~nm})$ nor (ii) a (55, 55) (pore diameter $7.5 \mathrm{~nm}$ ), carbon nanotubes that present a very well-known geometry, contrarily to an experimental polycarbonate nanopore membrane and a hydrophobic character close to experimental conditions. All the simulated nanotubes presented a length of $5 \mathrm{~nm}$, and the solvent was precisely composed of (i) 8017 water molecules, $15 \mathrm{Na}^{+}$, and $15 \mathrm{Cl}^{-}$ions. The complete system (a total of 28361 atoms, periodic box of $38 \times 38 \times 194 \AA^{3}$ ) was progressively filled by 6 gA monomers placed randomly in front of the nanopore (only one is shown for clarity in Figure 6a). The total simulation time is 294 ns. (ii) 30564 water molecules, $18 \mathrm{Na}^{+}$, and $18 \mathrm{Cl}^{-}$ions. The complete system (a total of 106948 atoms, periodic box of $85 \times 85 \times 142 \AA^{3}$ ) was progressively filled by $36 \mathrm{gA}$ monomers placed randomly in front of the nanopore (Figure $6 \mathrm{~b}$ ). The total simulation time is $368 \mathrm{~ns}$.

\section{RESULTS AND DISCUSSION}

Solid-State Membrane Fabrication. The schematic process for the synthesis of the hybrid membrane is summarized in Figure 1. 

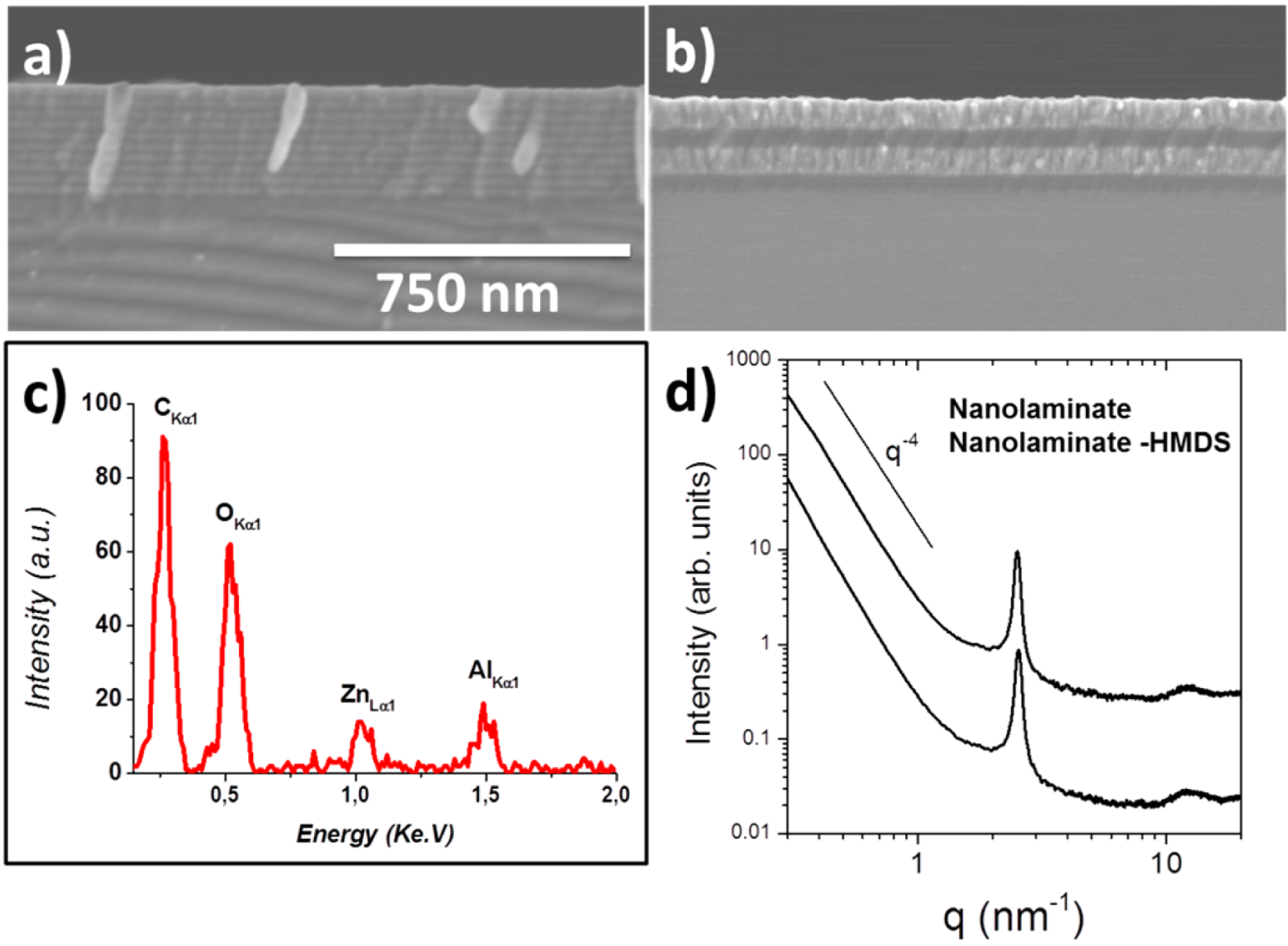

Figure 2. SEM images of nanolaminate cross sections with bilayer thicknesses of (a) $24.8 \mathrm{~nm}$ and (b) $124 \mathrm{~nm}$. (c) $\mathrm{EDX}$ measurement of $\mathrm{ZnO} / \mathrm{Al}_{2} \mathrm{O}_{3}$ nanolaminates deposited on the PET membrane and (d) SAXS profiles obtained on the PC track-etched membrane (Whatman-Nucleopore, diameter $200 \mathrm{~nm}$, density $7 \times 10^{8}$ pore $\mathrm{cm}^{-2}$ ) after 35 sequences of 5 cycles $\mathrm{Al}_{2} \mathrm{O}_{3} / 5$ cycles $\mathrm{ZnO}$, before and after HMDS coating (curves were arbitrarily shifted for clarity).
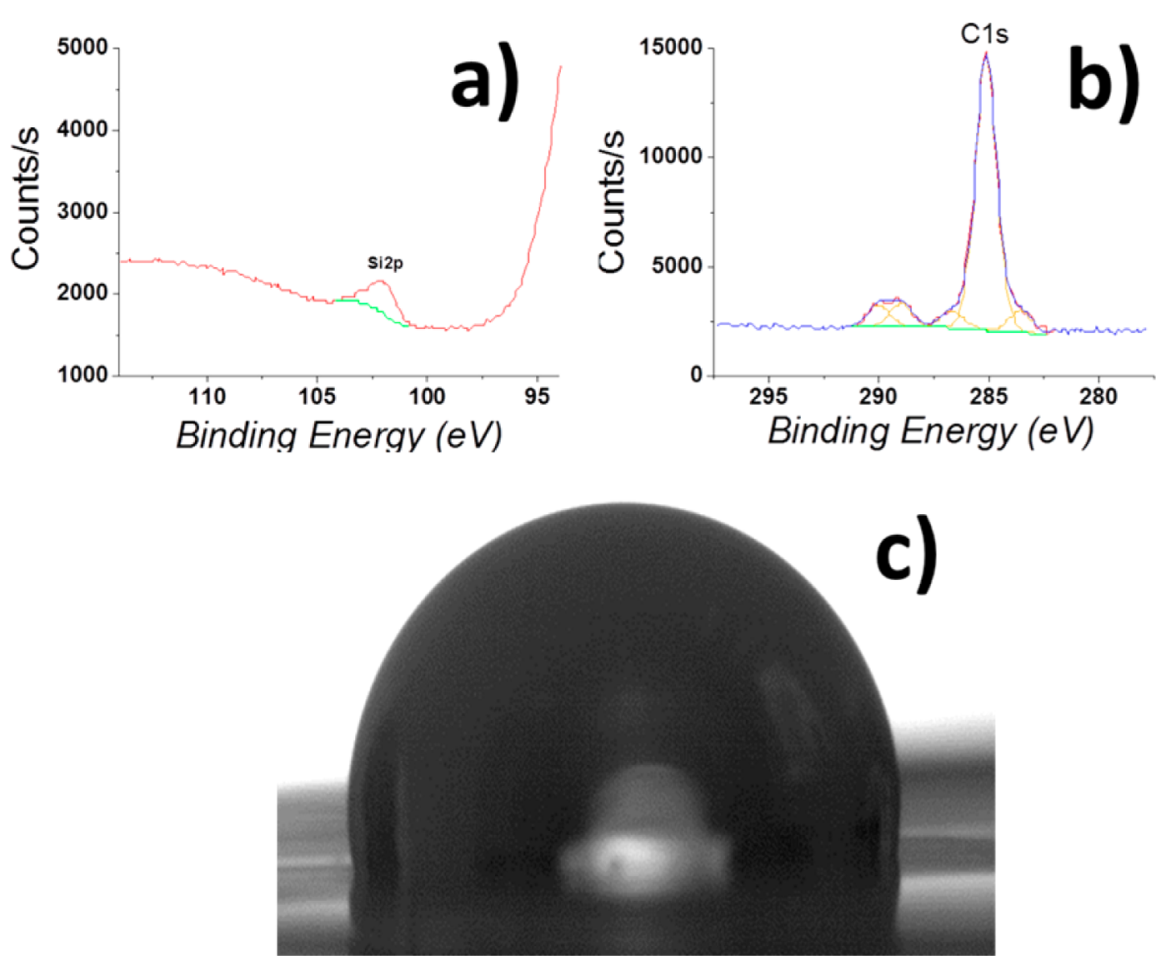

Figure 3. XPS spectrum performed on a HMDS modified PET membrane: (a) Si 2p scan, (b) C 1s scan, and (c) contact angle of a water droplet on the HMDS modified PET membrane.

The control of the shape and the surface state is the most important point for membrane protein confinement. The cylindrical pores on PET film have been obtained by chemical etching $\left(\mathrm{NaOH}, 5 \mathrm{~min}, 50{ }^{\circ} \mathrm{C}\right)$ after $\mathrm{UV}$ exposition which induces a well cylindrical pore shape. ${ }^{51}$
The average diameter pore size $(36 \mathrm{~nm})$ has been estimated by conductivity measurements (S1) at different $\mathrm{NaCl}$ concentrations (from 0.9 to $300 \mathrm{mM}$ ). The chemical etching of PET induces the formation of carboxyl groups on the surface of the membrane and on the surface of the pores walls ${ }^{52,53}$ 
which provide numerous sites for the conformal coating by the atomic layer deposition method (ALD).${ }^{54} \mathrm{~A}$ homogeneous film in the inner part of the pore was prepared using ALD to reduce the pore diameter to a range lower than $10 \mathrm{~nm}^{55,56} \mathrm{~A}$ nanolaminate layer of $\mathrm{Al}_{2} \mathrm{O}_{3} / \mathrm{ZnO}$ (Figure 2) has been used to conserve the flexibility ${ }^{37}$ of the membrane and to reduce the roughness ${ }^{57}$ of the deposit film inside the nanopores. $\mathrm{Al}_{2} \mathrm{O}_{3}$ and $\mathrm{ZnO}$ were deposited at $60{ }^{\circ} \mathrm{C}$ by alternating five cycles of TMA and $\mathrm{H}_{2} \mathrm{O}$ and five cycles of DEZ and $\mathrm{H}_{2} \mathrm{O}$. In this study five, six, and seven bilayers have been deposited, respectively, to reduce the $36 \mathrm{~nm}$ diameter to $10.6 \mathrm{~nm}\left(\mathrm{nP}_{11}\right), 5.7\left(\mathrm{nP}_{6}\right)$, and $\sim 2 \mathrm{~nm}$ $\left(\mathrm{nP}_{2}\right)$, respectively (Figure 1$)$. The growth rate per cycle for both materials was determined using SEM (Figure 2a, $2 b$ ) on monolayers and multilayers of $\mathrm{ZnO}$ and $\mathrm{Al}_{2} \mathrm{O}_{3}$. The growth per cycle was about $2.1 \AA$ /cycle for $\mathrm{ZnO}$ and $2 \AA$ /cycle for $\mathrm{Al}_{2} \mathrm{O}_{3}$ at $60{ }^{\circ} \mathrm{C} .{ }^{51}$

A bilayer thickness of $2.48 \mathrm{~nm}$ determined by SAXS measurement has been obtained inside the nanopores for $\mathrm{Al}_{2} \mathrm{O}_{3} / \mathrm{ZnO}$ nanolaminates. Figure $2 \mathrm{~d}$ shows the SAXS measurement performed on 35 sequences of 5 cycles $\mathrm{Al}_{2} \mathrm{O}_{3} / 5$ cycles $\mathrm{ZnO}$ on the PC track-etched membrane with a pore diameter of $200 \mathrm{~nm}$. The SAXS profile presents two main features: A structure peak appears at $q=2.53 \mathrm{~nm}^{-1}$ (i.e., 2.48 $\mathrm{nm}$ in the real space) which corresponds to the width of a double layer deposited by ALD. A $q^{-4}$ slope is observed in the low $q$ region, characteristic of a sharp interface between the air in pores and the layers deposited by ALD. ${ }^{58,59}$ This proves the quality of the deposition in terms of width control and homogeneity. The roughness of the films was examined using AFM measurement. The measurement performed on thin film deposited on the Si substrate shows that the roughness of the nanolaminates $\left(R_{q}=0.25, \mathrm{SI}\right)$ decreases significantly compared to a single layer of $\mathrm{ZnO}\left(R_{q}=0.34, \mathrm{SI}\right)$ and $\mathrm{Al}_{2} \mathrm{O}_{3}\left(R_{q}=0.32\right.$, $\mathrm{SI})$. This could be related to the amorphous nature of the $\mathrm{ZnO} / \mathrm{Al}_{2} \mathrm{O}_{3}$ nanolaminates. ${ }^{37,57}$

Chemical composition was investigated using EDX. As observed in a typical spectrum, shown in Figure $2 \mathrm{c}, \mathrm{Zn}, \mathrm{Al}$, and $\mathrm{O}$ have been detected. Rutherford backscattering spectrometry (RBS) analysis shows that $\mathrm{ZnO}$ and $\mathrm{Al}_{2} \mathrm{O}_{3}$ are stoichiometric. $^{37,38,57}$ Elastic recoil detection analysis (ERDA) and mass spectrometry measurements show the presence of a partially hydroxylated phase on the surface of the nanolaminate samples. $37,38,57$

After the ALD deposition, the hydrophilic surface due to the $-\mathrm{OH}$ terminal on $\mathrm{ZnO}$ was converted to a hydrophobic $\left(\left(\mathrm{CH}_{3}\right)_{3} \mathrm{Si}-\right)$ surface terminal by a hexamethyldisilazane (HMDS) treatment. After HMDS grafting of the sample, the SAXS profile (Figure $2 \mathrm{~d}$ ) appears unchanged in the $q$ vector range accessible by our experimental setup. This is the proof that this grafting did not alter the quality of the ALD coating. The success of the grafting has been attested by XPS measurement (Figures $3 a, b$ and Tables S3a and S3b in Supporting Information). Silicon in low content was detected ( $\mathrm{Si} 2 \mathrm{p}$ binding energies $100.38 \mathrm{eV}$ ) that corresponds to the Si$\mathrm{CH}_{3}$ bond (Figure 3a). ${ }^{60}$ The last attribution is confirmed by the binding energy $(283.20 \mathrm{eV})$ measured for the carbon element (C 1s) (Figure 3b). ${ }^{60}$ The hydrophobicity was confirmed by the determination of a contact angle of $92{ }^{\circ} \mathrm{C}$ on the treated HMDS surface (Figure 3c). In addition, HMDS plays the role of a passivation layer preventing the corrosion of $\mathrm{ZnO}^{61}$ in $\mathrm{NaCl}$ medium.

Hydrophobic Nanopore Conductance. $\mathrm{NaCl}$ conductivities through the nanopores obtained by ALD have been measured for concentrations from 0.9 to $300 \mathrm{mM}$ before gA confinement. The experiments performed on different pore sizes exhibit the linear current dependence on voltage of Ohms law (examples in Figure SI 1b, Supporting Information). In addition, the one pore conductance $G=\sigma \kappa$, where $\sigma$ is the conductivity and $\kappa=S / L(S=$ pore section area; $L=$ pore length), increases linearly with $\mathrm{NaCl}$ concentration (Figure 4 ).

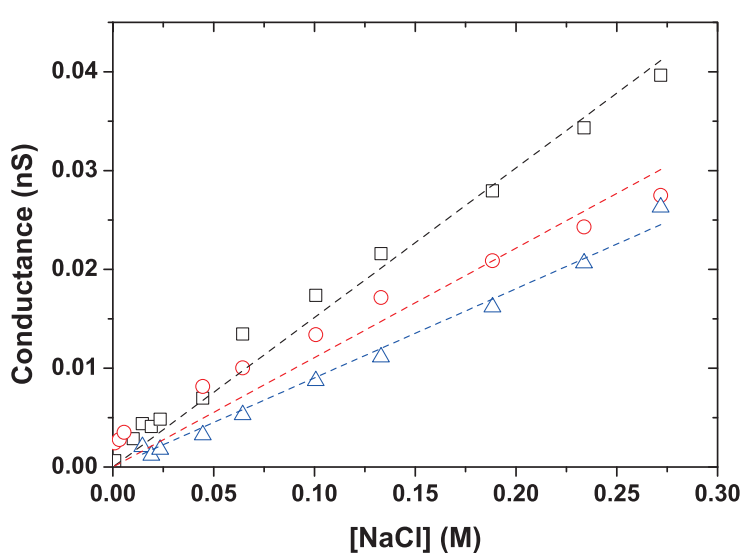

Figure 4. Evolution of conductance as a function of $\mathrm{NaCl}$ concentration for nanopore diameter $10.6 \mathrm{~nm}$ (black square), 5.7 $\mathrm{nm}$ (red circle), and $\sim 2 \mathrm{~nm}$ (blue triangle).

Taking $\sigma$ as the bulk conductivity, the length $\kappa_{\text {exp }}$, deduced from conductance measurement, was found for the larger pores $\mathrm{nP}_{11}$ and $\mathrm{nP}_{6}$ to be of the expected order of magnitude of the pore dimensions. However, it deviates significantly for the pore $\mathrm{nP}_{2}$ where the measured conductance was much higher than the expected one. In this range of pore radius, confinement of electrolytes could induce a large deviation of the conductivity from the bulk value. Moreover, roughness of the walls could also be an important parameter. The roughness of surface due to ALD deposition is $0.25 \mathrm{~nm}$ (Supporting Information) which is not negligible in regard to the mean radius $\sim 2 \mathrm{~nm}$. Understanding of the mechanisms which induce these conductivities requires a more thorough study and is not in the scope of the present work. Such a work is in progress in our laboratory using measurements on single nanopores. In the present case, these experiments have been performed for comparison with the same 100 nanopore membranes having confined gA.

Gramicidin Insertion. gA insertion inside a hydrophobic nanopore reduced by ALD and modified by HMDS has been performed under water solvent. gA characterization inside $\sim 100$ pore membranes cannot be performed by usual techniques such as circular dichroism and FTIR due to the too small amounts of confined gA. The proof of gA confinement was obtained by electrical measurement.

Influence of gA Insertion on Ionic Transport. Presently, all attempts to confine biological ionic channels inside a nanopore have shown a loss or a modification of their ionic selectivity. ${ }^{3,4}$ Indeed, in biological membranes gA selectivity in the presence of monovalent ions is induced by head to head dimer structure as the junction between the monomers blocks the anions and allows the transport of cations. It has been shown that this dimer structure is lost in aqueous solution. ${ }^{50}$ Thus, according to experimental conditions, it can be assumed that head to head structure is lost before the gA confinement. 
Table 2. Permeation Ratio and Conductivity Experiments of Nanopore Confined gA

\begin{tabular}{cccccccc} 
pore size & $g_{\mathrm{Max}\left(\mathrm{Na}^{+}\right)}(\mathrm{nS})$ & $K_{\mathrm{M}\left(\mathrm{Na}^{+}\right)}(\mathrm{M})$ & $g_{\mathrm{Max}\left(\mathrm{Cl}^{-}\right)}(\mathrm{nS})$ & $K_{\mathrm{M}\left(\mathrm{Cl}^{-}\right)}(\mathrm{M})$ & $\lambda_{\text {out }}\left(\mathrm{nS} \cdot \mathrm{M}^{-1}\right)$ & $0.978 \times 10^{-4}$ & 0.21 \\
$\mathrm{nP}_{11}-\mathrm{gA}$ & 0.02 & 0.018 & 0.03 & 1.23 & 0.027 & 0.00 \\
$\mathrm{nP}_{6}-\mathrm{gA}$ & 0.77 & 0.360 & 0.370 & 0.74 & $4.40 \times 10^{-4}$ & 0.99 \\
$\mathrm{nP}_{2}-\mathrm{gA}$ & 0.75 & 0.982 & 0.785 \\
\hline
\end{tabular}
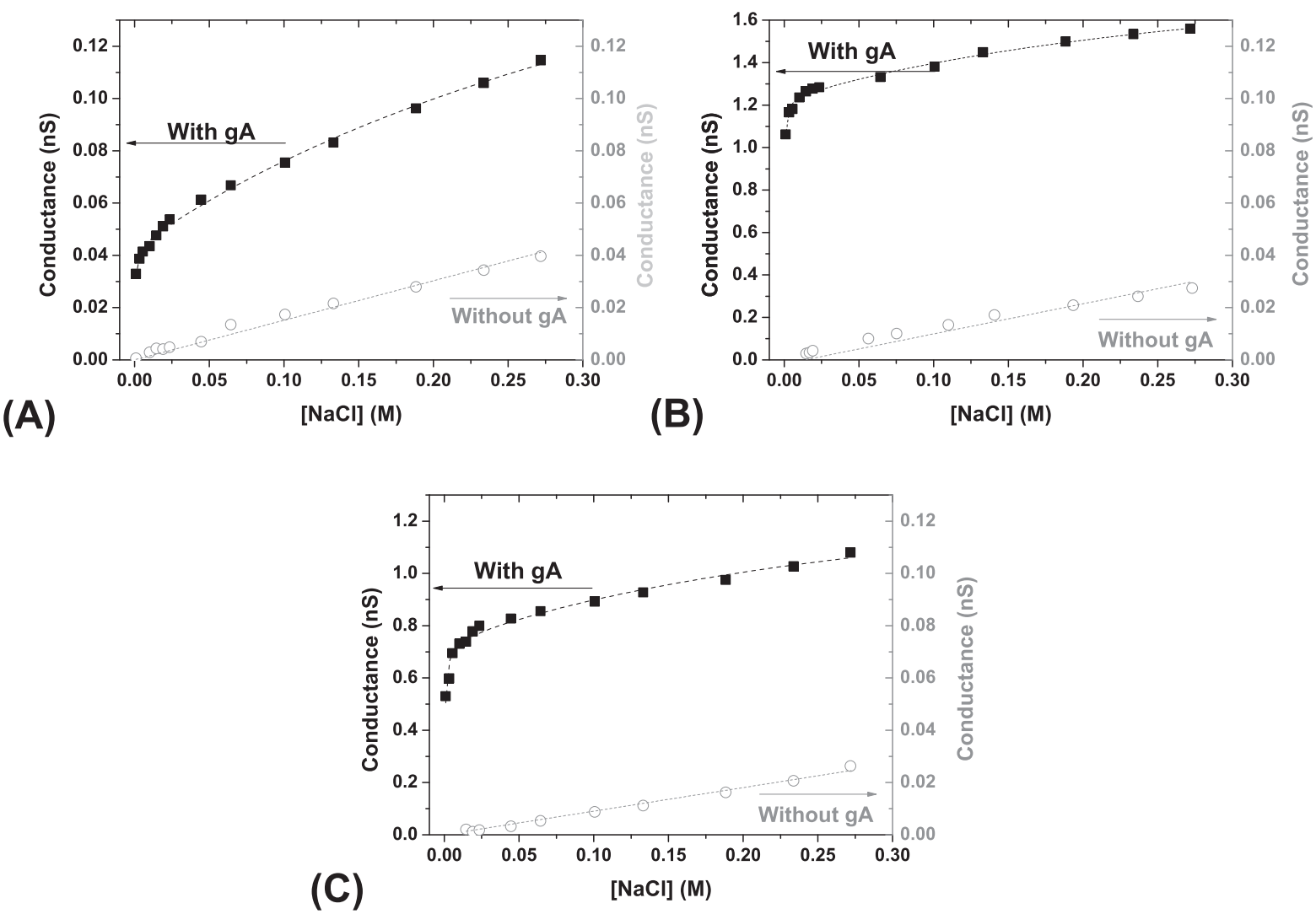

Figure 5. Evolution of nanopore conductance with and without confined $\mathrm{gA}$ under $\mathrm{NaCl}$ symmetrical concentration. Experimental measurements are fitted by curves obtained through the resolution of eq $3:$ (a) $\mathrm{nP}_{11}$-gA (black square) and $\mathrm{nP}_{11}$ (gray round), (b) $\mathrm{nP}_{6}$-gA (black square) and $\mathrm{nP}_{6}$ (gray round), and (c) $\mathrm{nP}_{2}$-gA (black square) and $\mathrm{nP}_{2}$ (gray round).

Two kinds of experiments were carried out with gA-loaded PET membranes separating two compartments: first, the analysis of transfer of sodium chloride through the membrane by diffusion under a concentration gradient was performed to determine the selectivity of confined gA via the inversion potential; second, the analysis of current intensity as a function of voltage $(I / V)$ with the same salt concentration in the two compartments was carried out as a function of concentration to check the possible saturation as observed in biological channels.

In the first series of experiments, the average transport of electrolyte through the membrane is unidirectional, and the different interactions of sodium cation and chloride anion with the inner pores lead to different mobilities of the ions. According to the Goldman-Hodgkin-Katz equation (eq 3), the permeability ratio $P_{\mathrm{Na}+} / P_{\mathrm{Cl}}$ ( (Table 2 ) is deduced from the inversion potential $E_{\text {rev }}$. For all experiments, we have obtained a ratio $P_{\mathrm{Na}+} / P_{\mathrm{Cl}-}<1$. It means that confined gA exhibits a better permeability to chlorine than to sodium ions. The smaller is the pore diameter, and the higher is the ratio, which suggests that increasing confinement favors the cation mobility. However, the higher value corresponds yet to a higher permeability of the anion, contrary to the selectivity of the channel in biological membranes. In such membranes, the ionic transport properties through gA are strongly dependent on its structure. First, the cationic permeation is affected by different helical structures that gA can adopt depending on the phospholipid composition of the membranes. ${ }^{62}$ Second, the impermeability to $\mathrm{Cl}^{-}$is due to changes in the hydration state near head-head connection of two gAs and in the $\beta$-helix structure. ${ }^{11,63}$ It is very likely that, when $\mathrm{gA}$ is confined inside the nanopore, the dimer assembly broken in solution is not recovered which induced therefore the permeability of $\mathrm{Cl}^{-}$. This result is in accordance with our previous work where gA has been confined inside the commercial polycarbonate track-etched membrane (diameter $15 \mathrm{~nm})^{3}$

The second experiment series aimed to obtain information on transport kinetics of both $\mathrm{Na}^{+}$and $\mathrm{Cl}^{-}$. In this case, the ionic transport through the membrane is bidirectional. The measured $I / V$ curves show the linear current dependence on voltage of the Ohm's law (examples on Figure SI 1b, Supporting Information). The membrane conductance with gA as a function of salt concentration exhibits two regimes (Figure 5): a steep increase at low concentration and a much smaller one at high concentration. Even in the range of high concentrations, the variation is still one order of magnitude larger than without gA (Figure 5). The conductance in the low concentration domain is several orders of magnitude larger. This suggests the gA specific function of enhancing the 


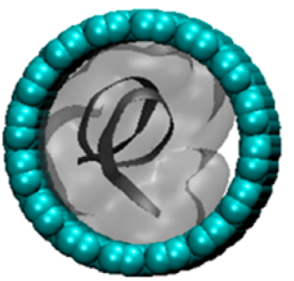

(a)

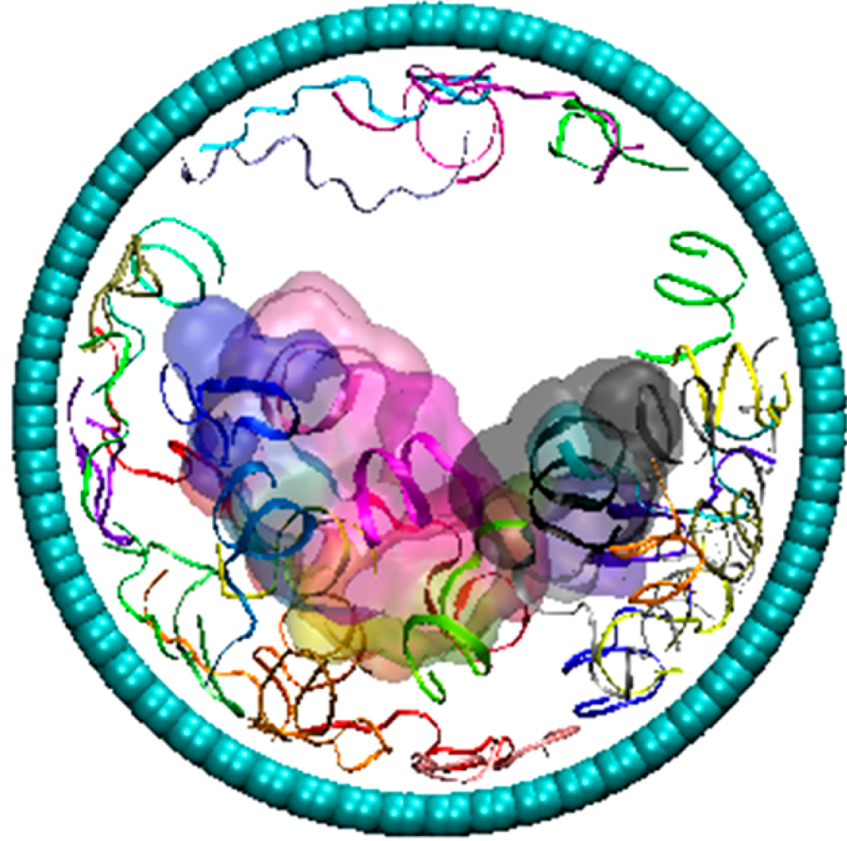

(b)

Figure 6. Snapshots of gA confinement inside a hydrophobic nanopore (blue circles) of diameter $2.1 \mathrm{~nm}$ (a) and $7.5 \mathrm{~nm}$ (b) obtained by dynamic molecular simulation (gA are shown in ribbon representation with its surface modeling when they are folded): (a) 2 gAs have been incorporated inside the nanopore and stabilized during $20 \mathrm{~ns}$ (the second protein is not shown for clarity), and (b) 36 gAs have been inserted progressively inside the pore during $270 \mathrm{~ns}$. Some are unfolded principally on the pore wall, while others keep their helix structure partially.

transport of ions with respect to bulk. The nonlinear increase with the concentration is similar to the behavior observed for biological ionic channels including gramicidin. ${ }^{64,65}$ Concentration-dependent ion permeation kinetics in single-ion occupancy is commonly described by kinetic models involving the Michaelis-Menten (eq 4).

$$
G(C)=g_{\max } \frac{C}{K_{M}+C}
$$

where $G(C)$ is the nanopore conductance at ion concentration (bulk) $C$; $g_{\mathrm{Max}}$ is the maximum (saturation) conductivity; and $K_{\mathrm{M}}$ is the Michaelis constant which is referred to the dissociation constant in the equilibrium theory. This model assumes that the ionic channel is selective to only one electrolyte and that the conductance reaches an asymptotic value $G_{\operatorname{Max}}$ where all ionic channel sites are occupied. The present system is not as simple as such because the transport of the two ions exists and two types of populations for each ion are likely as ion pathways outside the gramicidin channels cannot be excluded. Considering this, we extended the model to $\mathrm{Na}^{+}$and $\mathrm{Cl}^{-}$cotransport, where ionic pore conductance can be described as the sum of both cation and anion conductances through confined gA $\left(G_{\mathrm{gA}}\right)$ and a conductance outside gA $\left(G_{\text {out }}\right)($ eq 5$)$.

$$
G_{\mathrm{T}}=\left(G_{\mathrm{Na}^{+}}+G_{\mathrm{Cl}^{-}}\right) \mathrm{gA}+G_{\text {out }}
$$

Assuming that, at the entrance, each electrolyte should be assimilated to single-ion occupancy inside gA, it is possible to combine eqs 4 and 5 .

$$
G_{\mathrm{T}}=\frac{g_{\max \left(\mathrm{Na}^{+}\right)}\left[\mathrm{Na}^{+}\right]}{K_{\mathrm{M}\left(\mathrm{Na}^{+}\right)}+\left[\mathrm{Na}^{+}\right]}+\frac{g_{\max \left(\mathrm{Cl}^{-}\right)}\left[\mathrm{Cl}^{-}\right]}{K_{\mathrm{M}\left(\mathrm{Cl}^{-}\right)}+\left[\mathrm{Cl}^{-}\right]}+\lambda_{\text {out }}[\mathrm{NaCl}]
$$

Experimental data have been fitted by this model and parameters reported in Table 2. Regarding the anionic behavior demonstrated without electric field $P_{\mathrm{Na}+6} / P_{\mathrm{Cl}-}<1$, and the same dependency between $G_{\text {ion }}$ and $P_{\text {ion }}{ }^{66}$ the values of fitted parameters $\left(g_{\mathrm{Max}}\right.$ and $\left.K_{\mathrm{M}}\right)$ can be assigned in such a way that $\mathrm{G}_{\mathrm{Cl}-}>\mathrm{G}_{\mathrm{Na}+}$.

The results reported in Table 2 show that parameter $\lambda_{\text {out }}$ is equal to zero excepted for $\mathrm{nP}_{11}-\mathrm{gA}$. In addition, the $\mathrm{nP}_{11}-\mathrm{gA}$ conductances are lower than the $\mathrm{nP}_{6}$-gA and $\mathrm{nP}_{2}$-gA ones. This result suggests the increasing relative contribution of the ion transport through gramicidin when the pore size becomes very small. The value $\lambda_{\text {out }}\left(0.21 \mathrm{nS} \mathrm{M}^{-1}\right)$ obtained for $\mathrm{nP}_{11}$-gA is of the same order of magnitude as in the absence of gramicidin (0.15 $\left.\mathrm{nS} \mathrm{M} \mathrm{M}^{-1}\right)$, suggesting a bulk-like ionic environment, gramicidin excluded. The lack of $G_{\text {out }}$ for both $\mathrm{nP}_{6}-\mathrm{gA}$ and $\mathrm{nP}_{2^{-}}$ gA shows that electrolyte transport occurs mainly through gramicidin and that conductance outside gA can be considered as negligible. It means that ions are docked inside gA sites, and thus it suggests an organization in $\beta$-helix gA structure, at least partially, such as in biological conditions. ${ }^{67}$

From the theoretical point of view, to have an insight on the structural arrangement of the confined proteins, we have performed, using the same protocol and parameters as previously, ${ }^{3}$ dynamic molecular simulations of gA inside hydrophobic nanopores (diameters 2.1-7.5 nm) modeled here by an assembly of carbon atoms that mimics the experimental pore (Figure 6). For $7.5 \mathrm{~nm}$ diameter pore size, the simulations show a gA confinement in two steps: (1) The first gAs are adsorbed on the nanopore surface and lose their helix structure, and (2) the following gAs are located in the pore center and keep the helix structure but lose the head to head dimer structures. Here, the small gA concentration used experimentally leads to only partial filling of the pore center for high nanopore diameter (Figure $6 \mathrm{~b}$ ), in accordance with the 
significant contribution of bulk-like domains in the total conductance (Table 2). For $2 \mathrm{~nm}$ diameter pore size, the simulation shows that only one gA can occupy the pore with its saved helix structure in these high confining conditions (Figure $6 a)$, in accordance with the negligible contribution of bulk-like domains in the total conductance deduced for the smaller pores (Table 2).

According to eq 3, for a given $\mathrm{NaCl}$ concentration the ratio $G_{\mathrm{Na}+} / G_{\mathrm{Cl}}$ is higher for $\mathrm{nP}_{2}$-gA than for $\mathrm{nP}_{6}-\mathrm{gA}$, typically for $\mathrm{NaCl}$ bulk concentration $250 \mathrm{mM}\left(0.257\right.$ for $\mathrm{nP}_{6}$-gA and 0.409 for $\mathrm{nP}_{2}-\mathrm{gA}$, respectively). These values differ slightly from those obtained with the ratio $P_{\mathrm{Na}+} / P_{\mathrm{Cl}}$ - under dissymmetrical concentration, probably because of the difference in the experimental conditions. However, the increases of both ratios induced by the pore size reduction are similar (factor 1.6 under symmetrical conditions and factor 2.0 under dissymmetrical condition). If we focus on electrolyte transport inside gA, it can be noted that $K_{\mathrm{M}(\mathrm{Cl})}<K_{\mathrm{M}(\mathrm{Na}+)}$. This Michaelis constant can be associated to dissociation constants. We have attributed the lowest value to the chloride ion based on the preceding experiment on diffusion under a concentration gradient, which revealed the affinity of gramicidin for the chloride anion. However, gA affinity with $\mathrm{Cl}^{-}$decreases with nanopore diameter, and thus it can be imagined to recover partially its selectivity properties for a hydrophobic pore diameter of 0.8 $\mathrm{nm}$.

\section{CONCLUSION}

In summary, we report on the tuning of track-etched PET membranes using atomic layer deposition of $\mathrm{Al}_{2} \mathrm{O}_{3} / \mathrm{ZnO}$ nanolaminate. The obtained biomimetic membranes keep their flexibility and have homogeneous nanopores with low roughness inside the pores. Then gA confinement inside the nanopores $(10.6,5.7, \sim 2 \mathrm{~nm})$ has been performed. The resulting nanopore exhibits an anionic behavior explained by the loss of gA head-head dimer structure. The conductance measurements reveal for the first time an enhanced ionic transport mechanism through gA inside a polymeric solid-state nanopore as in biological membranes. However, the trend observed when decreasing the pore size might leave hopefully possibilities to transpose biological mechanisms of ionic transport when an ionic channel is directly confined inside a synthetic nanopore

\section{ASSOCIATED CONTENT}

\section{S Supporting Information}

Conductance of nanopore before reduction, typical $I / V$ curves, and AFM and XPS table. This material is available free of charge via the Internet at http://pubs.acs.org.

\section{AUTHOR INFORMATION}

\section{Corresponding Author}

*Sébastien Balme. E-mail: sebastien.balme@univ-montp2.fr. Tel.: 33 467149118. Mikhael Bechelany. E-mail: mikhael. bechenaly@univ-montp2.fr. Tel.: 33467149167.

\section{Author Contributions}

${ }^{\#}$ These authors contributed equally.

\section{Notes}

The authors declare no competing financial interest.

\section{ACKNOWLEDGMENTS}

Computations have been performed on the supercomputer facilities of the Mésocentre de calculs de Franche-Comté.

\section{REFERENCES}

(1) Guo, W.; Cao, L. X.; Xia, J. C.; Nie, F. Q.; Ma, W.; Xue, J. M.; Song, Y. L.; Zhu, D. B.; Wang, Y. G.; Jiang, L. Energy Harvesting with Single-Ion-Selective Nanopores: A Concentration-Gradient-Driven Nanofluidic Power Source. Adv. Funct. Mater. 2010, 20, 1339-1344.

(2) Siwy, Z. S.; Howorka, S. Engineered Voltage-Responsive Nanopores (vol 39, pg 1115, 2010). Chem. Soc. Rev. 2010, 39, 5067-5067.

(3) Balme, S.; Janot, J.-M.; Berardo, L.; Henn, F.o.; Bonhenry, D.; Kraszewski, S.; Picaud, F.; Ramseyer, C. New Bioinspired Membrane Made of a Biological Ion Channel Confined into the Cylindrical Nanopore of a Solid-State Polymer. Nano Lett. 2011, 11, 712-716.

(4) Thiele, D.; Kraszewski, S.; Balme, S.; Picaud, F.; Janot, J.-M.; Déjardin, P. Structure and Ionic Selectivity of a Hybrid Polyene/ Artificial Polymer Solid State Membrane. Soft Matter 2013, 9, 684691.

(5) Kocer, A.; Tauk, L.; Dejardin, P. Nanopore Sensors: From Hybrid to Abiotic Systems. Biosens. Bioelectron. 2012, 38, 1-10.

(6) Hall, A. R.; Scott, A.; Rotem, D.; Mehta, K. K.; Bayley, H.; Dekker, C. Hybrid Pore Formation by Directed Insertion of AlphaHaemolysin into Solid-State Nanopores. Nat. Nanotechnol. 2010, 5, 874-877.

(7) Shvinka, N. E.; Caffier, G. Selectivity for Cations in Potassium and Gramicidin Channels of the Muscle Fibre Membrane. Biomed. Biochim. Acta 1988, 47, 481-487.

(8) Sawyer, D. B.; Williams, L. P.; Whaley, W. L.; Koeppe, R. E.; Andersen, O. S. Gramicidin-A, Gramicidin-B, and Gramicidin-C Form Structurally Equivalent Ion Channels. Biophys. J. 1990, 58, 1207-1212.

(9) Wallace, B. A. Common Structural Features in Gramicidin and Other Ion Channels. Bioessays 2000, 22, 227-234.

(10) Allen, T. W.; Andersen, O. S.; Roux, B. Ion Permeation through a Narrow Channel: Using Gramicidin to Ascertain All-Atom Molecular Dynamics Potential of Mean Force Methodology and Biomolecular Force Fields. Biophys. J. 2006, 90, 3447-3468.

(11) Hinton, J. F.; Fernandez, J. Q.; Shungu, D. C.; Millett, F. S. Thermodynamic Parameters for the Binding of Divalent-Cations to Gramicidin-a Incorporated into a Lipid Environment by Ti-205 Nuclear Magnetic-Resonance. Biophys. J. 1989, 55, 327-330.

(12) Roux, B. Valence Selectivity of the Gramicidin Channel: A Molecular Dynamics Free Energy Perturbation Study. Biophys. J. 1996, $71,3177-3185$

(13) Balme, S.; Picaud, F.; Kraszewski, S.; Dejardin, P.; Janot, J. M.; Lepoitevin, M.; Campomanes, J.; Ramseyer, C.; Henn, F. Controlling Ionic Selectivity in Bio-Inspired Systems: Potassium Selectivity and Proton Blocking in Hybrid Biological/Solid-State Polymer Nanopore Membrane. Nanoscale 2013, 5, 3961-3968.

(14) Strathmann, H. Membrane Separation Processes: Current Relevance and Future Opportunities. AIChE J. 2001, 47, 1077-1087.

(15) Velleman, L.; Triani, G.; Evans, P. J.; Shapter, J. G.; Losic, D. Structural and Chemical Modification of Porous Alumina Membranes. Microporous Mesoporous Mater. 2009, 126, 87-94.

(16) Stevens, G. B.; Reda, T.; Raguse, B. Energy Storage by the Electrochemical Reduction of $\mathrm{CO}_{2}$ to $\mathrm{CO}$ at a Porous Au Film. J. Electroanal. Chem. 2002, 526, 125-133.

(17) Gilani, N.; Daryan, J. T.; Rashidi, A.; Omidkhah, M. R. Separation of Methane-Nitrogen Mixtures Using Synthesis Vertically Aligned Carbon Nanotube Membranes. Appl. Surf. Sci. 2012, 258, 4819-4825.

(18) Lakshmi, B. B.; Patrissi, C. J.; Martin, C. R. Sol-Gel Template Synthesis of Semiconductor Oxide Micro- And Nanostructures. Chem. Mater. 1997, 9, 2544-2550.

(19) Marichy, C.; Bechelany, M.; Pinna, N. Atomic Layer Deposition of Nanostructured Materials for Energy and Environmental Applications. Adv. Mater. 2012, 24, 1017-1032. 
(20) Willinger, M.-G.; Neri, G.; Rauwel, E.; Bonavita, A.; Micali, G.; Pinna, N. Vanadium Oxide Sensing Layer Grown on Carbon Nanotubes by a New Atomic Layer Deposition Process. Nano Lett. 2008, 8, 4201-4204.

(21) Du, X.; George, S. M. Thickness Dependence of Sensor Response for CO Gas Sensing by Tin Oxide Films Grown Using Atomic Layer Deposition. Sens. Actuators, B 2008, 135, 152-160.

(22) Venkatesan, B. M.; Dorvel, B.; Yemenicioglu, S.; Watkins, N.; Petrov, I.; Bashir, R. Highly Sensitive, Mechanically Stable Nanopore Sensors for DNA Analysis. Adv. Mater. 2009, 21, 2771-2776.

(23) Martinson, A. B. F.; Elam, J. W.; Hupp, J. T.; Pellin, M. J. ZnO Nanotube Based Dye-Sensitized Solar Cells. Nano Lett. 2007, 7, 2183-2187.

(24) Park, K.; Zhang, Q.; Garcia, B. B.; Zhou, X.; Jeong, Y.-H.; Cao, G. Effect of an Ultrathin $\mathrm{TiO}_{2}$ Layer Coated on Submicrometer-Sized $\mathrm{ZnO}$ Nanocrystallite Aggregates by Atomic Layer Deposition on the Performance of Dye-Sensitized Solar Cells. Adv. Mater. 2010, 22, 2329-2332.

(25) Park, K.; Zhang, Q.; Garcia, B. B.; Cao, G. Effect of Annealing Temperature on $\mathrm{TiO}_{2}-\mathrm{ZnO}$ Core-Shell Aggregate Photoelectrodes of Dye-Sensitized Solar Cells. J. Phys. Chem. C 2011, 115, 4927-4934.

(26) Hierso, J.; Sel, O.; Ringuede, A.; Laberty-Robert, C.; Bianchi, L.; Grosso, D.; Sanchez, C. Design, Synthesis, Structural and Textural Characterization, and Electrical Properties of Mesoporous Thin Films Made of Rare Earth Oxide Binaries. Chem. Mater. 2009, 21, 21842192.

(27) Brahim, C.; Chauveau, F.; Ringuede, A.; Cassir, M.; Putkonen, M.; Niinistoe, L. $\mathrm{ZrO}_{2}-\mathrm{In}_{2} \mathrm{O}_{3}$ Thin Layers with Gradual Ionic to Electronic Composition Synthesized by Atomic Layer Deposition for SOFC Applications. J. Mater. Chem. 2009, 19, 760-766.

(28) Gerritsen, E.; Emonet, N.; Caillat, C.; Jourdan, N.; Piazza, M.; Fraboulet, D.; Boeck, B.; Berthelot, A.; Smith, S.; Mazoyer, P. Evolution of Materials Technology for Stacked-Capacitors in $65 \mathrm{~nm}$ Embedded-DRAM. Solid-State Electron. 2005, 49, 1767-1775.

(29) Paracchino, A.; Laporte, V.; Sivula, K.; Graetzel, M.; Thimsen, E. Highly Active Oxide Photocathode for Photoelectrochemical Water Reduction. Nat. Mater. 2011, 10, 456-461.

(30) Tan, L. K.; Kumar, M. K.; An, W. W.; Gao, H. Transparent, Well-Aligned $\mathrm{TiO}_{2}$ Nanotube Arrays with Controllable Dimensions on Glass Substrates for Photocatalytic Applications. ACS Appl. Mater. Interfaces 2010, 2, 498-503.

(31) Dameron, A. A.; Davidson, S. D.; Burton, B. B.; Carcia, P. F.; McLean, R. S.; George, S. M. Gas Diffusion Barriers on Polymers Using Multilayers Fabricated by $\mathrm{Al}_{2} \mathrm{O}_{3}$ and Rapid $\mathrm{SiO}_{2}$ Atomic Layer Deposition. J. Phys. Chem. C 2008, 112, 4573-4580.

(32) Ghosh, A. P.; Gerenser, L. J.; Jarman, C. M.; Fornalik, J. E. ThinFilm Encapsulation of Organic Light-Emitting Devices. Appl. Phys. Lett. 2005, 86.

(33) Park, S. H. K.; Oh, J.; Hwang, C. S.; Lee, J. I.; Yang, Y. S.; Chu, H. Y. Ultrathin Film Encapsulation Of an OLED by ALD. Electrochem. Solid State Lett. 2005, 8, H21-H23.

(34) Potscavage, W. J.; Yoo, S.; Domercq, B.; Kippelen, B. Encapsulation of Pentacene/C-60 Organic Solar Cells with $\mathrm{Al}_{2} \mathrm{O}_{3}$ Deposited by Atomic Layer Deposition. Appl. Phys. Lett. 2007, 90, 253511.

(35) Fumagalli, L.; Natali, D.; Sampietro, M.; Peron, E.; Perissinotti, F.; Tallarida, G.; Ferrari, S. $\mathrm{Al}_{2} \mathrm{O}_{3}$ as Gate Dielectric for Organic Transistors: Charge Transport Phenomena in Poly-(3-hexylthiophene) Based Devices. Org. Electron. 2008, 9, 198-208.

(36) Mailhot, B.; Rivaton, A.; Gardette, J. L.; Moustaghfir, A.; Tomasella, E.; Jacquet, M.; Ma, X. G.; Komvopoulos, K. Enhancement of the Photoprotection and Nanomechanical Properties of Polycarbonate by Deposition of Thin Ceramic Coatings. J. Appl. Phys. 2006, 99, 104310.

(37) Raghavan, R.; Bechelany, M.; Parlinska, M.; Frey, D.; Mook, W. M.; Beyer, A.; Michler, J.; Utke, I. Nanocrystalline-to-Amorphous Transition in Nanolaminates Grown by Low Temperature Atomic Layer Deposition and Related Mechanical Properties. Appl. Phys. Lett. 2012, 100 .
(38) Whitby, J. A.; Oestlund, F.; Horvath, P.; Gabureac, M.; Riesterer, J. L.; Utke, I.; Hohl, M.; Sedlacek, L.; Jiruse, J.; Friedli, V.; Bechelany, M.; Michler, J. High Spatial Resolution Time-of-Flight Secondary Ion Mass Spectrometry for the Masses: A Novel Orthogonal ToF FIB-SIMS Instrument with In Situ AFM. Adv. Mater. Sci. Eng. 2012, 2012, 180437.

(39) Sakamoto, S.; Philippe, L.; Bechelany, M.; Michler, J.; Asoh, H.; Ono, S. Ordered Hexagonal Array of Au Nanodots on Si Substrate Based on Colloidal Crystal Templating. Nanotechnology 2008, 19, 405304.

(40) Bachmann, J.; Zierold, R.; Chong, Y. T.; Hauert, R.; Sturm, C.; Schmidt-Grund, R.; Rheinlander, B.; Grundmann, M.; Gosele, U.; Nielsch, K. A Practical, Self-Catalytic, Atomic Layer Deposition of Silicon Dioxide. Angew. Chem., Int. Ed. 2008, 47, 6177-6179.

(41) Elias, J.; Bechelany, M.; Utke, I.; Erni, R.; Hosseini, D.; Michler, J.; Philippe, L. Urchin-Inspired Zinc Oxide As Building Blocks for Nanostructured Solar Cells. Nano Energy 2012, 1, 696-705.

(42) Barry, P. H.; Lynch, J. W. Liquid Junction Potentials and SmallCell Effects in Patch-Clamp Analysis. J. Membr. Biol. 1991, 121, 101117.

(43) Pickard, W. Generalizations of the Goldman-Hodgkin-Katz equation. Math. Biosci. 1976, 30, 99-111.

(44) Phillips, J. C.; Braun, R.; Wang, W.; Gumbart, J.; Tajkhorshid, E.; Villa, E.; Chipot, C.; Skeel, R. D.; Kalé, L.; Schulten, K. Scalable Molecular Dynamics with NAMD. J. Comput. Chem. 2005, 26, 17811802.

(45) Feller, S. Constant Pressure Molecular Dynamics Simulation: The Langevin Piston Method. J. Chem. Phys. 1995, 103, 4613.

(46) Darden, T.; York, D.; Pedersen, L. Particle Mesh Ewald: An N. $\log (\mathrm{N})$ Method for Ewald Sums in Large Systems. J. Chem. Phys. 1993, 98, 10089-10092.

(47) MacKerell, A. D.; Bashford, D.; Bellott, R. L.; Dunbrack, J. D.; Evanseck, M. J.; Field, S.; Fischer, J.; Gao, H.; Guo, S.; Ha, D.; JosephMcCarthy, L.; Kuchnir, K.; Kuczera, F. T. K.; Lau, C.; Mattos, S.; Michnick, T.; Ngo, D. T.; Nguyen, B.; Prodhom, W. E.; Reiher, B.; Roux, M.; Schlenkrich, J. C.; Smith, R.; Stote, J.; Straub, M.; Watanabe, J.; Wirkiewicz-Kuczera, D.; Yin; Karplus, M. All-Atom Empirical Potential for Molecular Modeling and Dynamics Studies of Proteins. J. Phys. Chem. B 1998, 102, 3586-3616.

(48) Jorgensen, W. Comparison of Simple Potential Functions for Simulating Liquid Water. J. Chem. Phys. 1983, 79, 926.

(49) Bedrov, D.; Smith, G. D.; Davande, H.; Li, L. Passive Transport of C60 Fullerenes through a Lipid Membrane: A Molecular Dynamics Simulation Study. J. Phys. Chem. B 2008, 112, 2078-2084.

(50) Bonhenry, D.; Kraszewski, S.; Picaud, F.; Ramseyer, C.; Balme, S.b.; Janot, J. M.; Henn, F. Stability of the Gramicidin-A Channel Structure in View of Nanofiltration: A Computational and Experimental Study. Soft Matter 2011, 7, 10659.

(51) Sirijarukul, S.; Balanzat, E.; Vasina, E. N.; Dejardin, P. Flat Sheet Membrane with Controlled Variation of Pore Density and Pore Size in a Direction Parallel to the Surface. J. Membr. Sci. 2007, 296, 185-194.

(52) Dejardin, P.; Vasina, E. N.; Berezkin, V. V.; Sobolev, V. D.; Volkov, V. I. Streaming Potential in Cylindrical Pores of Poly(ethylene terephthalate) Track-Etched Membranes: Variation of Apparent Zeta Potential with Pore Radius. Langmuir 2005, 21, 4680-4685.

(53) Powell, M. R.; Cleary, L.; Davenport, M.; Shea, K. J.; Siwy, Z. S. Electric-Field-Induced Wetting and Dewetting in Single Hydrophobic Nanopores. Na. Nanotechnol. 2011, 6, 798-802.

(54) Jur, J. S.; Spagnola, J. C.; Lee, K.; Gong, B.; Peng, Q.; Parsons, G. N. Temperature-Dependent Subsurface Growth during Atomic Layer Deposition on Polypropylene and Cellulose Fibers. Langmuir 2010, 26, 8239-8244.

(55) Chen, Z.; Jiang, Y. B.; Dunphy, D. R.; Adams, D. P.; Hodges, C.; Liu, N. G.; Zhang, N.; Xomeritakis, G.; Jin, X. Z.; Aluru, N. R.; Gaik, S. J.; Hillhouse, H. W.; Brinker, C. J. DNA Translocation through an Array of Kinked Nanopores. Nat. Mater. 2010, 9, 667-675.

(56) Canlas, C. P.; Lu, J. L.; Ray, N. A.; Grosso-Giordano, N. A.; Lee, S.; Elam, J. W.; Winans, R. E.; Van Duyne, R. P.; Stair, P. C.; 
Notestein, J. M. Shape-Selective Sieving Layers on an Oxide Catalyst Surface. Nature Chem. 2012, 4, 1030-1036.

(57) Elam, J. W.; Sechrist, Z. A.; George, S. M. $\mathrm{ZnO} / \mathrm{Al}_{2} \mathrm{O}_{3}$ Nanolaminates Fabricated by Atomic Layer Deposition: Growth and Surface Roughness Measurements. Thin Solid Films 2002, 414, 43-55.

(58) G., P. X-ray low angle scattering of dense colloid systems. Part I. (Die Röntgenkleinwinkelstreuung von dichtgepackten kolloiden systemen. I. Teil.). Koll. Zeit. 1951, 124, 83-114.

(59) Porod, G. Die Röntgenkleinwinkelstreuung von dichtgepackten kolloiden Systemen. Koll. Zeit. 1952, 125, 51-57.

(60) Puniredd, S. R.; Assad, O.; Haick, H. Highly Stable Organic Modification of Si(111) Surfaces: Towards Reacting Si with Further Functionalities while Preserving the Desirable Chemical Properties of Full Si-C Atop Site Terminations. J. Am. Chem. Soc. 2008, 130, 91849185.

(61) Cimatu, K. A.; Mahurin, S. M.; Meyer, K. A.; Shaw, R. W. Nanoscale Chemical Imaging of Zinc Oxide Nanowire Corrosion. J. Phys. Chem. C 2012, 116, 10405-10414.

(62) Smart, O. S.; Goodfellow, J. M.; Wallace, B. A. The Pore Dimensions of Gramicidin A. Biophys. J. 1993, 65, 2455-2460.

(63) Allen, T. W.; Andersen, O. S.; Roux, B. Molecular Dynamics Potential of Mean Force Calculations As a Tool for Understanding Ion Permeation and Selectivity in Narrow Channels. Biophys. Chem. 2006, 124, 251-267.

(64) Neher, E.; Sandblom, J.; Eisenman, G. Ionic Selectivity, Saturation, and Block in Gramicidin-a Channels 0.2. Saturation Behavior of Single Channel Conductances and Evidence for Existence of Multiple Binding-Sites in Channel. J. Membr. Biol. 1978, 40, 97116.

(65) Sandblom, J.; Eisenman, G.; Neher, E. Ionic Selectivity, Saturation and Block in Gramicidin-a Channels - 0.1. Theory for Electrical-Properties of Ion-Selective Channels Having 2 Pairs of Binding-Sites and Multiple Conductance States. J. Membr. Biol. 1977, 31, 383-417.

(66) Strickholm, A. Ionic Permeability of $\mathrm{K}, \mathrm{Na}$, and $\mathrm{Cl}$ in PotassiumDepolarized Nerve - Dependency on Ph, Cooperative Effects, and Action of Tetrodotoxin. Biophys. J. 1981, 35, 677-697.

(67) Roux, B.; Karplus, M. Ion-Transport in a Model Gramicidin Channel - Structure and Thermodynamics. Biophys. J. 1991, 59, 961981. 